(2) Open Access Full Text Article

\title{
Design, synthesis, and antimelanogenic effects of (2-substituted phenyl-I,3-dithiolan-4-yl)methanol derivatives
}

\author{
This article was published in the following Dove Press journal: \\ Drug Design, Development and Therapy \\ 16 March 2017 \\ Number of times this article has been viewed
}

\begin{abstract}
The authors designed and synthesized 17 (2-substituted phenyl-1,3-dithiolan-4-yl) methanol (PDTM) derivatives to find a new chemical scaffold, showing excellent tyrosinaseinhibitory activity. Their tyrosinase-inhibitory activities were evaluated against mushroom tyrosinase at $50 \mu \mathrm{M}$, and five of the PDTM derivatives (PDTM3, PDTM7-PDTM9, and PDTM13) were found to inhibit mushroom tyrosinase more than kojic acid or arbutin, the positive controls. Of seventeen PDTMs, PDTM3 (half-maximal inhibitory concentration 13.94 $\pm 1.76 \mu \mathrm{M}$ ), with a 2,4-dihydroxyphenyl moiety, exhibited greatest inhibitory effects (kojic acid half-maximal inhibitory concentration $18.86 \pm 2.14 \mu \mathrm{M}$ ). Interestingly, PDTM compounds with no hydroxyl group, PDTM7-PDTM9, also had stronger inhibitory activities than kojic acid. In silico studies of interactions between tyrosinase and the five PDTMs suggested their binding affinities were closely related to their tyrosinase-inhibitory activities. Cell-based experiments performed using B16F10 mouse-skin melanoma cells showed that PDTM3 effectively inhibited melanogenesis and cellular tyrosinase activity. A cell-viability study conducted using B16F10 cells indicated that the antimelanogenic effect of PDTM3 was not attributable to its cytotoxicity. Kinetic studies showed PDTM3 competitively inhibited tyrosinase, indicating binding to the tyrosinase-active site. We found that PDTM3 with a new chemical scaffold could be a promising candidate for skin-whitening agents, and that the 1,3-dithiolane ring could be used as a chemical scaffold for potent tyrosinase inhibition.
\end{abstract}

Keywords: tyrosinase inhibitor, melanogenesis, 1,3-dithiolane, PDTM

\section{Introduction}

For the past few decades, tyrosinase inhibitors have been of considerable interest, due to the key role played by tyrosinase in melanogenesis. Melanin is produced using a combination of enzymatically catalyzed and chemical reactions. The biosynthetic pathway responsible for melanin production was initially elucidated by Raper $^{1}$ and Mason $^{2}$ and recently modified by Cooksey et $\mathrm{al}^{3}$ and Schallreuter et al. ${ }^{4}$ Melanogenesis is initiated by the enzyme tyrosinase, which catalyses the first two oxidative steps in the melanin biosynthetic pathway: the oxidations of L-tyrosine to L-dopa followed by L-dopa to L-dopaquinone (Figure 1). These two steps are also the rate-determining steps in melanin biosynthesis, because physiological $\mathrm{pH}$ can continue spontaneously subsequent steps. ${ }^{5}$ The dopaquinone produced in the second step is converted to cysteinyldopa by glutathione or cysteine, and finally to pheomelanin, which is responsible for yellow to red colors of mammal skin, or to dopachrome by auto-oxidation and finally eumelanin, which is responsible for brown/black colors of mammal skin (Figure 1). Melanin protects human skin from harmful ultraviolet radiation, and also determines cc) ${ }_{\mathrm{BY}} \mathrm{NC}$ and incorporate the Creative Commons Attribution - Non Commercial (unported, v3.0) License (http://creativecommons.org/licenses/by-n/3.0/). By accessing the work you hereby accept the Terms. Non-commercial uses of the work are permitted without any further permission from Dove Medical Press Limited, provided the work is properly attributed. For permission for commercial use of this work, please see paragraphs 4.2 and 5 of our Terms (https://www.dovepress.com/terms.php). 


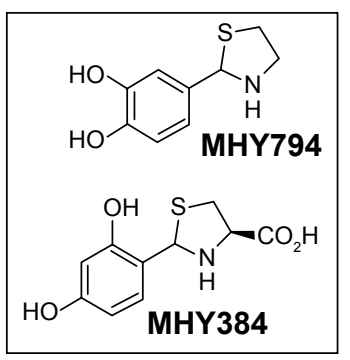

Strong competitive tyrosinase inhibitors

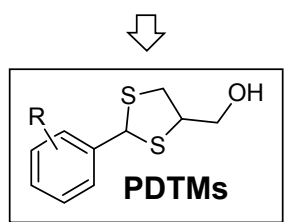

Tyrosinase inhibition ??
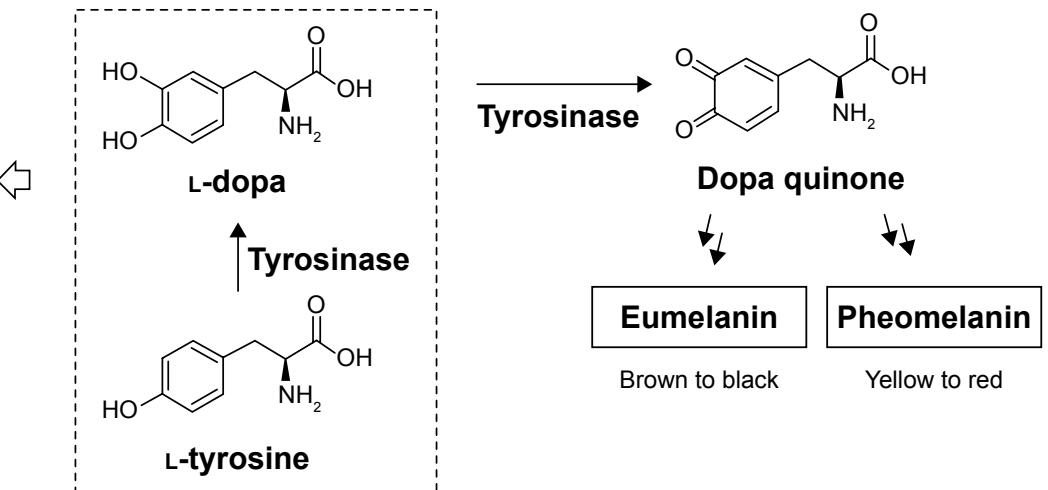

Natural substrates for tyrosinase

Figure I Rationale used to design PDTM derivatives as tyrosinase inhibitors. Abbreviation: PDTM, (2-substituted phenyl-1,3-dithiolan-4-yl)methanol.

phenotypic appearance. On the other hand, excessive melanin accumulation in skin can cause hyperpigmentation-associated diseases and cosmetic problems, such as freckles, melasma, and senile lentigines.

Tyrosinase is widely distributed in bacteria, fungi, insects, plants, and animals, including humans, and is responsible for the colors of human skin and hair and the undesirable browning of fruit and vegetables. ${ }^{6}$ Undesirable enzymatic browning and diseases associated with hyperpigmentation in skin have encouraged scientists to seek novel potent tyrosinase inhibitors for use as skin-whitening and antibrowning agents. Many tyrosinase inhibitors have been discovered to date, ${ }^{7-9}$ but relatively few have been approved as skin-whitening materials, due to safety concerns or weak whitening effects.

In our previous studies, on the basis of structures of L-tyrosine and L-dopa, natural substrates of tyrosinase, we designed two potential tyrosinase inhibitors with a thiazolidine ring (MHY384 and MHY794; Figure 1) and synthesized them by condensation of an appropriate benzaldehyde and L-cysteine or cysteamine hydrochloride. These two compounds were identified to be potent competitive tyrosinase inhibitors and to effectively reduce melanogenesis in HRM2 hairless mice. ${ }^{10,11}$ In addition to directly inhibiting tyrosinase activity, MHY384 inhibited tyrosinase expression by suppressing the cyclic adenosine monophosphate-PKA ${ }^{10}$ and NO-induced cyclic guanosine monophosphate- $\mathrm{PKG}^{12,13}$ pathways, and MHY794 also suppressed tyrosinase expression induced by NO-mediated melanogenesis signaling. ${ }^{11}$ These positive results and the fact that divalent $-\mathrm{S}-$ is a classical isostere of divalent $-\mathrm{NH}$ - encouraged us to synthesize derivatives with a dithiolane ring as a surrogate for the thiazolidine ring commonly existing in MHY384 and MHY794, in order to find novel tyrosinase inhibitors.

In the present study, as part of our ongoing efforts to find a new and strong chemical scaffold for inhibition of tyrosinase and develop new tyrosinase inhibitors, we synthesized a class of structurally novel (2-substituted phenyl-1,3-dithiolan-4-yl) methanol (PDTM) derivatives (Figure 1) and investigated their antimelanogenic effects using mushroom tyrosinase and cell-based assays. In this study, kojic acid and arbutin were used as a positive control for tyrosinase-inhibitory activity, because kojic acid is one of the most commonly used positive controls for evaluation of tyrosinase inhibition and arbutin is clinically used as a whitening agent.

\section{Materials and methods Materials}

Unless otherwise noted, all commercially available reagents L-tyrosine (code T3754), L-dopa (code PHR1271), kojic acid (code K3125), MTT (3-(4,5-dimethyl-2-thiazolyl)2,5-diphenyl-2H-tetrazolium bromide) (code M2128), PMSF (phenylmethylsulfonyl fluoride) (code P7626), Triton X-100 (4-(1,1,3,3-tetramethylbutyl)phenylpolyethylene glycol) (code T8787), potassium hydrogen phosphate (code P9666), potassium dihydrogen phosphate (code PHR1330), 2,3-dimercapto-1-propanol (code 64046), 1,4-dioxane (code 296309), sulfuric acid (code 339741), and benzaldehydes were purchased from Sigma-Aldrich (St Louis, MO, USA). Fetal bovine serum, Dulbecco's Modified Eagle's Medium, phosphate-buffered saline (PBS), penicillin, streptomycin, 
and trypsin were purchased from Thermo Fisher Scientific (Waltham, MA, USA). Mushroom tyrosinase (code T3824) and $\alpha$-melanocyte-stimulating hormone $(\alpha-\mathrm{MSH}$; code M4135) were also purchased from Sigma-Aldrich. ${ }^{1} \mathrm{H}$ and ${ }^{13} \mathrm{C}$ nuclear magnetic resonance (NMR) spectra were recorded on Varian Unity Inova 400 and Varian Unity AS 500 instruments (Agilent Technologies, Santa Clara, CA, USA). Low-resolution mass spectrometry (MS) and high-resolution MS data were obtained on an Expression CMS (Advion, Ithaca, NY, USA) and a 6530 Accurate Mass quadrupole time-of-flight liquid-chromatography mass spectrometer (Agilent), respectively. Synthesis of PDTM1-PDTM17 was accomplished in our laboratory.

\section{General procedure for synthesis of PDTMI-PDTMI 7}

To a stirred solution of 2,3-dimercapto-1-propanol (100 mg, $0.80 \mathrm{mmol})$ in 1,4-dioxane $(1 \mathrm{~mL})$ were added a solution of sulfuric acid ( 0.1 equivalence) in 1,4-dioxane $(1 \mathrm{~mL})$ and an appropriate benzaldehyde (1.1 equivalence) subsequently. After being stirred at room temperature for 10 minutes, the reaction mixture was stirred at $70^{\circ} \mathrm{C}$ for 40 minutes to 1 hour. The mixture was then partitioned between ethyl acetate and water, and the organic layer was dried over anhydrous $\mathrm{MgSO}_{4}$, filtered, and evaporated. The residue obtained was purified using silica-gel column chromatography to give pure PDTM products: PDTM1-PDTM17. ${ }^{14}$ Structural characterization $\left({ }^{1} \mathrm{H}\right.$ and ${ }^{13} \mathrm{C}$ NMR and mass data of all PDTMs and 1-D and 2-D NMR spectra of some PDTMs) of synthesized compounds is provided in Supplementary materials.

\section{Inhibition of mushroom tyrosinase by PDTMI-PDTMI 7}

The inhibitory effects of PDTM analogues on mushroom tyrosinase were explored with minor modifications, as described previously in our work. ${ }^{15}$ Each compound $(10 \mu \mathrm{L}$, final concentration $50 \mu \mathrm{M}$ ) was mixed with substrate solution $(170 \mu \mathrm{L})$, prepared from $14.7 \mathrm{mM}$ potassium phosphate buffer (pH 6.5) and $293 \mu \mathrm{M}$ L-tyrosine solution (1:1, v/v), in each well of a 96-well plate. To each well, mushroom tyrosinase solution $(20 \mu \mathrm{L}, 1,000 \mathrm{U} / \mathrm{mL})$ was added and incubated for 30 minutes at $37^{\circ} \mathrm{C}$. Contents of dopachrome formed in wells were determined by measuring optical densities at $475 \mathrm{~nm}$ using a VersaMax microplate reader (Molecular Devices, Sunnyvale, CA, USA). Kojic acid and arbutin were used as positive controls. All experiments were performed in triplicate. Inhibition rates of tyrosinase were calculated thus:

$$
\text { Inhibition }(\%)=100 \times[1-(\mathrm{A} / \mathrm{B})]
$$

where A indicates the optical density of the test compound and $\mathrm{B}$ represents the optical density of the control.

Half-maximal inhibitory concentration $\left(\mathrm{IC}_{50}\right)$ is the concentration of a compound that inhibits a standard $50 \%$ response. $\mathrm{IC}_{50}$ is derived from the $x$-axis on an inhibitor-concentration versus product-formation curve, and is determined from the alignment of the dose-response curve on the dependent $y$-axis. In the present study, dose-dependent inhibition experiments were performed in triplicate to determine the $\mathrm{IC}_{50}$ of compounds. According to the inhibition percentage of five doses (final concentration 10, 20, 30, 40, and $50 \mu \mathrm{M})$ in each experiment, the log-linear curves and their equations were determined. Individual $\mathrm{IC}_{50}$ values were then calculated as the concentration when the $y$-axis equaled $50 \%$ inhibition. The results from three experiments are shown.

\section{Analysis of the nature of mushroom tyrosinase inhibition}

To elucidate the nature of the inhibitory effect of PDTM3 on mushroom tyrosinase, kinetic studies were performed. PDTM3 $(10 \mu \mathrm{L}[0,5,10$, or $25 \mu \mathrm{M}$ final concentration]) was added to $170 \mu \mathrm{L}$ L-tyrosine solution $(0.5,1,2$, or $4 \mathrm{mM}$ final concentration) and then mixed with mushroom tyrosinase solution $(20 \mu \mathrm{L}, 1,000 \mathrm{U} / \mathrm{mL})$ in each well of a 96 -well plate. After the mixture was incubated for 30 minutes at $37^{\circ} \mathrm{C}$, the contents of dopachrome produced in wells were determined by measuring optical densities at $475 \mathrm{~nm}$ using a microplate reader. All experiments were carried out in triplicate. For determination of the nature of inhibition, a Lineweaver-Burk plot was used.

\section{Docking simulation of PDTM3 or kojic acid with tyrosinase}

The in silico docking simulation of protein-ligand was performed with AutoDock Vina using a systematic search technique and the 3-D structure of Agaricus bisporus tyrosinase (Protein Data Bank ID 2Y9X). ${ }^{16,17}$ In the crystal structure of tyrosinase, the binding site of L-tyrosine was used as a docking pocket. Simulation results were obtained from docking between tyrosinase and synthetic compounds (PDTM3, PDTM7, PDTM8, PDTM9, and PDTM13) or kojic acid. Before performing docking simulation with the compounds, 2-D structures of compounds were transformed into 3-D structures, charges of compounds were determined, and hydrogen atoms were inserted using ChemOffice (http:// www.cambridgesoft.com). LigandScout 3.1.2 was used for the prediction of possible interactions between ligands 
and tyrosinase and the identification of pharmacophores. Docking-simulation images of 17 PDTMs are provided in Supplementary materials.

\section{Cell culture}

Murine melanoma B16F10 cells were cultured in Dulbecco's Modified Eagle's Medium with penicillin-streptomycin $(100 \mathrm{IU} / 50 \mu \mathrm{g} / \mathrm{mL})$ and $10 \%$ heat-inactivated fetal bovine serum in a humidified atmosphere containing $5 \% \mathrm{CO}_{2}$ at $37^{\circ} \mathrm{C}$. B16F10 cells were cultured in 24-well plates for cell viability (MTT) assay, a melanin-content assay, and tyrosinase-activity assay. All experiments were performed at least three times to ensure reproducibility.

\section{Cell-viability assay}

MTT assays were performed in B16F10 cells for cellviability determination, as previously described. ${ }^{18}$ Cells seeded at a density of $5 \times 10^{4}$ cells/well in a 24 -well plate were allowed to adhere at $37^{\circ} \mathrm{C}$ for 24 hours in a $5 \%$ humidified $\mathrm{CO}_{2}$ atmosphere. On the following day, the cells were exposed to diverse concentrations of PDTM3 $(0,5$, 10 , or $25 \mu \mathrm{M})$ and incubated for 24 hours under the same conditions. To each well, MTT stock solution $(0.5 \mathrm{mg} / \mathrm{mL})$ was added and the plate incubated at $37^{\circ} \mathrm{C}$ for 2 hours. Formazan crystals isolated after removing supernatants were dissolved in dimethyl sulfoxide-ethanol $(200 \mu \mathrm{L}, 1: 1)$ and then moved to a 96-well plate. The optical density of each well was measured at $570 \mathrm{~nm}$ by an enzyme-linked immunosorbent assay reader. All experiments were performed in triplicate.

\section{Determination of melanogenesis level in BI6FIO cells}

Melanin-content assays with minor modifications were used in B16F10 cells for the inhibitory effects of PDTM3 on melanogenesis. ${ }^{19}$ Cells seeded at a density of $5 \times 10^{4}$ cells/well in a 24-well plate were allowed to adhere at $37^{\circ} \mathrm{C}$ in a humidified atmosphere containing $5 \% \mathrm{CO}_{2}$ overnight. The following day, the cells were exposed to $\alpha$-MSH $(1 \mu \mathrm{M})$ and PDTM3 $(0,5,10$, or $25 \mu \mathrm{M})$ or kojic acid $(25 \mu \mathrm{M})$, and the plate was incubated for 24 hours under the same conditions. After being washed twice with PBS, the cells were detached by incubation at $60^{\circ} \mathrm{C}$ in $200 \mu \mathrm{L}$ of $1 \mathrm{~N} \mathrm{NaOH}$ for 1 hour. The lysates were moved to a 96-well plate and optical densities measured at $405 \mathrm{~nm}$ by an enzyme-linked immunosorbent assay reader for calculation of mean percentage inhibitions of kojic acid and PDTM3. All experiments were carried out in triplicate.

\section{Tyrosinase-activity assay in BI6FIO cells}

By estimating the oxidation rate of $\mathrm{L}$-dopa, tyrosinase activities were evaluated with minor modifications, as described in previous work. ${ }^{20}$ Cells seeded at a density of $5 \times 10^{4}$ cell/well in a 24 -well plate were allowed to adhere at $37^{\circ} \mathrm{C}$ in a humidified atmosphere containing $5 \% \mathrm{CO}_{2}$ for 24 hours. The cells were exposed to $\alpha$-MSH $(1 \mu \mathrm{M})$ and PDTM $3(0,5,10$, or $25 \mu \mathrm{M})$ or kojic acid $(25 \mu \mathrm{M})$, and the plate was incubated under the same conditions for 24 hours. After being rinsed twice with PBS, the cells were lysed with $100 \mu \mathrm{L}$ lysis buffer containing $0.1 \mathrm{mM}$ PMSF $(5 \mu \mathrm{L}), 50 \mathrm{mM}$ PBS $(90 \mu \mathrm{L}$, $\mathrm{pH} 6.8)$, and $1 \%$ Triton $\mathrm{X}-100(5 \mu \mathrm{L})$ and frozen at $-80^{\circ} \mathrm{C}$ for 30 minutes. Lysates were thawed and centrifuged at $12,000 \mathrm{~g}$ for 30 minutes at $4{ }^{\circ} \mathrm{C}$ and supernatants $(80 \mu \mathrm{L})$ were combined with $10 \mathrm{mM} \mathrm{L-dopa}(20 \mu \mathrm{L})$ in a 96-well plate, which was then incubated for 30 minutes at $37^{\circ} \mathrm{C}$. Optical densities were calculated at $500 \mathrm{~nm}$, and the inhibitory activities of tyrosinase were determined thus:

$$
\text { Inhibition }(\%)=100 \times([\mathrm{A}-\mathrm{B}]-[\mathrm{C}-\mathrm{D}] /[\mathrm{A}-\mathrm{B}])
$$

where B and A are the optical densities of the blank before and after incubation, respectively, and $\mathrm{D}$ and $\mathrm{C}$ are the optical densities of the test compound before and after incubation, respectively.

\section{DPPH radical scavenging-activity assay}

The DPPH scavenging activity of PDTM derivatives was analyzed as described in a previous study, with minor modifications. ${ }^{21}$ DPPH methanol solution $(0.2 \mathrm{mM}, 180 \mu \mathrm{L})$ was mixed with a dimethyl sulfoxide solution $(20 \mu \mathrm{L})$ of each compound $(10 \mathrm{mM})$ in each well of a 96-well plate and then left at room temperature in the dark for 30 minutes. The absorbance of the resulting solutions was measured at $517 \mathrm{~nm}$ using a microplate reader. Scavenging capacity of each PDTM compound was compared to that of L-ascorbic acid, a positive control. All experiments were independently conducted in triplicate.

\section{Statistical analysis}

One way analysis of variance followed by Dunnett's test was used to determine whether group means differed significantly from those of controls. Welch's unpaired $t$-test was used to determine whether the effects of PDTM3 and kojic acid were significantly different. Statistical analysis was performed using GraphPad (GraphPad Software, La Jolla, CA, USA). All results are indicated as means \pm standard error of three independent experiments. Two sided $P$-values of $<0.05$ were considered statistically significant. 


\section{Results and discussion}

\section{Preparation of PDTMI-PDTMI7}

PDTM1-PDTM17 were synthesized as shown in Scheme 1. Heating 2,3-dimercapto-1-propanol and numerous suitably substituted benzaldehydes (1-17) in 1,4-dioxane in the presence of sulfuric acid afforded the desired PDTM products as solids or sticky oil. The structures of the final products were confirmed by ${ }^{1} \mathrm{H}$ and ${ }^{13} \mathrm{C} \mathrm{NMR}$, correlation spectroscopy, heteronuclear single-quantum correlation spectroscopy, heteronuclear multiple-bond correlation spectroscopy, and low- and high-resolution MS. The presence of the singlet corresponding to the $-\mathrm{SCH}(\mathrm{Ph}) \mathrm{S}-$ proton at $\delta=6.09-5.56 \mathrm{ppm}$ in ${ }^{1} \mathrm{H}$ NMR spectra confirmed the formation of a dithiolane ring between benzaldehydes and 2,3-mercapto-1-propanol. In ${ }^{1} \mathrm{H}$ NMR spectroscopic data of PDTMs, the 2-H peak appeared more downfield than the peaks of protons attached to $\mathrm{sp}^{3}$ carbon atoms, and the 4-H exomethylene and $5-\mathrm{H}_{2}$ peaks were observed more upfield in named order. In ${ }^{13} \mathrm{C}$ NMR spectroscopic data, apart from peaks from the phenyl ring, the carbon peak of exomethylene ( $\sim 64 \mathrm{ppm})$ was most downfield, followed in order by 4-C ( $\sim 58 \mathrm{ppm}), 2-\mathrm{C}$ $(\sim 55.3 \mathrm{ppm})$, and 5-C ( 41 ppm). Four products - PDTM6, PDTM12, PDTM13, and PDTM15 - were each obtained as a single racemate, whereas the others were obtained as

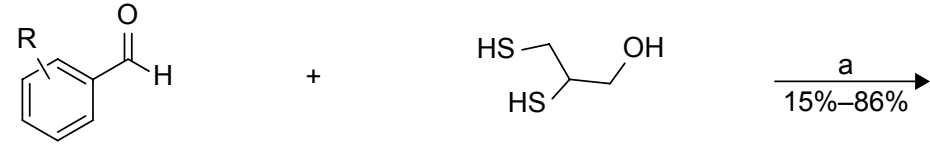

Substituted benzaldehydes 2,3-dimercapto-1-propanol

Benzaldehydes:<smiles>O=Cc1ccc(O)cc1</smiles><smiles>CCOc1cc(C=O)ccc1O</smiles><smiles>COc1ccc(C=O)c(OC)c1</smiles>

9<smiles>O=Cc1ccc(O)c(Br)c1</smiles><smiles>CC(C)(C)c1cc(C=O)cc(C(C)(C)C)c1O</smiles><smiles>O=Cc1ccc(O)c(O)c1</smiles><smiles>O=Cc1ccc(O)cc1O</smiles><smiles>COc1ccc(C=O)cc1O</smiles><smiles>O=Cc1ccccc1O</smiles>

10<smiles>O=Cc1cc(Br)c(O)c(C=O)c1</smiles><smiles>COc1ccc(C=O)cc1</smiles><smiles>COc1cc(C=O)cc(OC)c1OC</smiles><smiles>Cc1cc(C=O)ccc1O</smiles>

15<smiles>[R]c1ccccc1C1SC=C(CO)S1</smiles>

PDTM1-PDTM17<smiles>COc1cc(C=O)cc(C)c1O</smiles><smiles>COc1ccc(C=O)cc1OC</smiles><smiles>COc1cc(C=O)cc(OC)c1O</smiles><smiles>Cc1cc(C=O)cc(C)c1O</smiles>

Scheme I Structures of (2-substituted phenyl-I,3-dithiolan-4-yl)methanol (PDTM) derivatives, kojic acid, and arbutin, and reagents and conditions. Notes: $a, \mathrm{H}_{2} \mathrm{SO}_{4}$ in I,4-dioxane at $70^{\circ} \mathrm{C}$. $t$-Bu, tertiary butyl (group). 
a mixture of two racemates $([2 R, 4 R] /[2 S, 4 S]$ and $[2 R, 4 S] /$ $[2 S, 4 R], 1: 1-1: 1.5)$, the ratios of which were calculated using ${ }^{1} \mathrm{H}$ NMR spectroscopic data. The phenomenon in the product formation could not be explained simply by steric, electronic, and/or stereoelectronic effects. The tyrosinase-inhibition assay was performed without separation of the racemates.

\section{Inhibitory effects of PDTMI-PDTMI7 on mushroom tyrosinase}

The potentials of the 17 synthesized products, PDTM1PDTM17, to inhibit mushroom tyrosinase activity were examined using kojic acid ${ }^{22}$ and $\operatorname{arbutin}^{23}$ as positive controls. Inhibitions were determined using $293 \mu \mathrm{M}$ L-tyrosine as the substrate and synthetic compounds at a concentration of $50 \mu \mathrm{M}$. Tyrosinase inhibitions by kojic acid and arbutin were determined at 50 and $500 \mu \mathrm{M}$, respectively.

Three compounds - PDTM11 (3,4,5-trimethoxyphenyl), PDTM15 (4-hydroxy-3-methylphenyl), and PDTM17 (3,5-di-t-butyl-4-hydroxymethyl) - inhibited tyrosinase to the same extent as kojic acid and inhibited it more than arbutin (Table 1). Five PDTM derivatives - PDTM3 $(2,4-$ dihydroxyphenyl), PDTM7 (4-methoxyphenyl), PDTM8 (3,4dimethoxyphenyl), PDTM9 (2,4-dimethoxyphenyl), and PDTM13 (3-bromo-4-hydroxyphenyl) - inhibited tyrosinase more potently than kojic acid. $\mathrm{IC}_{50}$ values of these compounds were examined: $13.94 \pm 1.76 \mu \mathrm{M}$ (PDTM3), $16.47 \pm 2.36 \mu \mathrm{M}$ (PDTM7), 16.97 $\pm 2.99 \mu \mathrm{M}$ (PDTM8), $27.85 \pm 1.47 \mu \mathrm{M}$ (PDTM9), and 15.57 $\pm 3.31 \mu \mathrm{M}$ (PDTM13). The low $\mathrm{IC}_{50}$ values of PDTM3, PDTM7, PDTM8, and PDTM13 indicated that potency was stronger than that of kojic acid $(18.86 \pm 2.14 \mu \mathrm{M})$ and arbutin $(381.26 \pm 3.22 \mu \mathrm{M})$, which were used as positive controls. Interestingly, this result concurs with our previous finding that many analogues with a 2,4-dihydroxyphenyl moiety possess higher tyrosinaseinhibitory activity than kojic acid. ${ }^{10,13,24-32}$

The remaining PDTM derivatives had no (PDTM1 and PDTM2) or low inhibitory effect (PDTM4, PDTM5, PDTM6, PDTM10, PDTM12, PDTM14, and PDTM16) compared with kojic acid. According to our accumulated structure-activity relationship data, analogues with at least one hydroxyl group were more capable of inhibiting tyrosinase. Somewhat surprisingly, four PDTM derivatives with no hydroxyl group inhibited tyrosinase activity as much or more effectively than kojic acid. These were PDTM7 (4-methoxyphenyl), PDTM8 (3,4-dimethoxyphenyl), PDTM9 (2,4-dimethoxyphenyl), and PDTM11 (3,4,5-trimethoxyphenyl). Compounds (PDTM1-2, PDTM4-5, and PDTM12) with only a 4-hydroxyl group on the phenyl ring or an alkoxy or hydroxyl group at position 3
Table I Substitution patterns and tyrosinase-inhibitory activities by the synthesized compounds PDTMI-PDTMI7, kojic acid, and arbutin

\begin{tabular}{|c|c|c|c|c|c|}
\hline & & $\mathrm{R}^{4}$ & PDT & Or & \\
\hline Compound & $\mathbf{R}^{\prime}$ & $\mathbf{R}^{2}$ & $\mathbf{R}^{3}$ & $\mathbf{R}^{4}$ & $\begin{array}{l}\text { Tyrosinase } \\
\text { inhibition (\%) }\end{array}$ \\
\hline Kojic acid & & & & & $65.71 \pm 1.9$ \\
\hline Arbutin & & & & & $51.46 \pm 3.25$ \\
\hline PDTMI & $\mathrm{H}$ & $\mathrm{H}$ & $\mathrm{OH}$ & $\mathrm{H}$ & $\mathrm{NI}$ \\
\hline PDTM2 & $\mathrm{H}$ & $\mathrm{OH}$ & $\mathrm{OH}$ & $\mathrm{H}$ & $\mathrm{NI}$ \\
\hline PDTM3 & $\mathrm{OH}$ & $\mathrm{H}$ & $\mathrm{OH}$ & $\mathrm{H}$ & $77.99 \pm 0.34$ \\
\hline PDTM4 & $\mathrm{H}$ & $\mathrm{OMe}$ & $\mathrm{OH}$ & $\mathrm{H}$ & $7.44 \pm 2.41$ \\
\hline PDTM5 & $\mathrm{H}$ & $\mathrm{OEt}$ & $\mathrm{OH}$ & $\mathrm{H}$ & $7.8 \pm 2.45$ \\
\hline PDTM6 & $\mathrm{H}$ & $\mathrm{OH}$ & $\mathrm{OMe}$ & $\mathrm{H}$ & $56.23 \pm 1.48$ \\
\hline PDTM7 & $\mathrm{H}$ & $\mathrm{H}$ & $\mathrm{OMe}$ & $\mathrm{H}$ & $77.95 \pm 0.96$ \\
\hline PDTM8 & $\mathrm{H}$ & $\mathrm{OMe}$ & $\mathrm{OMe}$ & $\mathrm{H}$ & $73.76 \pm 0.97$ \\
\hline PDTM9 & OMe & $\mathrm{H}$ & $\mathrm{OMe}$ & $\mathrm{H}$ & $74.6 \pm 0.68$ \\
\hline PDTMIO & $\mathrm{OH}$ & $\mathrm{H}$ & $\mathrm{H}$ & $\mathrm{H}$ & $35.59 \pm 2.65$ \\
\hline PDTMII & $\mathrm{H}$ & $\mathrm{OMe}$ & $\mathrm{OMe}$ & OMe & $65.2 \pm 3.12$ \\
\hline PDTMI2 & $\mathrm{H}$ & $\mathrm{OMe}$ & $\mathrm{OH}$ & $\mathrm{OMe}$ & $38.7 \pm 3.14$ \\
\hline PDTMI3 & $\mathrm{H}$ & $\mathrm{Br}$ & $\mathrm{OH}$ & $\mathrm{H}$ & $75.27 \pm 0.97$ \\
\hline PDTMI4 & $\mathrm{H}$ & $\mathrm{Br}$ & $\mathrm{OH}$ & $\mathrm{Br}$ & $52.44 \pm 2.47$ \\
\hline PDTMI5 & $\mathrm{H}$ & $\mathrm{Me}$ & $\mathrm{OH}$ & $\mathrm{H}$ & $60.64 \pm 1.61$ \\
\hline PDTMI6 & $\mathrm{H}$ & $\mathrm{Me}$ & $\mathrm{OH}$ & $\mathrm{Me}$ & $50.1 \pm 1.81$ \\
\hline PDTMI7 & $\mathrm{H}$ & $t-B u$ & $\mathrm{OH}$ & $t-B u$ & $61.11 \pm 2.26$ \\
\hline
\end{tabular}

Notes: Results shown as mean \pm standard error of the mean $(n \geq 3)$ at a concentration of $50 \mu \mathrm{M}$ (with the exception of arbutin, at $500 \mu \mathrm{M}$ ). $\mathrm{R}^{\prime}-\mathrm{R}^{4}$, substituents on phenyl ring in the chemical structure of PDTMs.

Abbreviations: NI, no inhibition; PDTM, (2-substituted phenyl-1,3-dithiolan-4-yl) methanol; $t-\mathrm{Bu}$, tertiary butyl.

with a 4-hydroxyl group had low or no activity, whereas compounds (PDTM13-PDTM17) with an alkyl or bromo group at position 3 with a 4-hydroxyl group showed moderate-high tyrosinase-inhibitory activity. These structure-activity relationship results support the hypothesis that the tyrosinaseinhibitory activity of compounds with a 4-hydroxyl group is greatly affected by the type of 3 -substituent.

\section{Mode of mushroom tyrosinase inhibition by PDTM3}

Since PDTM3 inhibited mushroom tyrosinase most, a Lineweaver-Burk plot was used to determine the nature of its inhibitory effect. As depicted in Figure 2, a doublereciprocal plot was obtained, and all lines with different slopes intersected the $y$-axis at the same point. Therefore, $\mathrm{K}_{\mathrm{m}}$ (Michaelis constant) values increased gradually with concentration of PDTM3. Detailed kinetic-parameter values are shown in Table 2. On the other hand, maximum reaction 


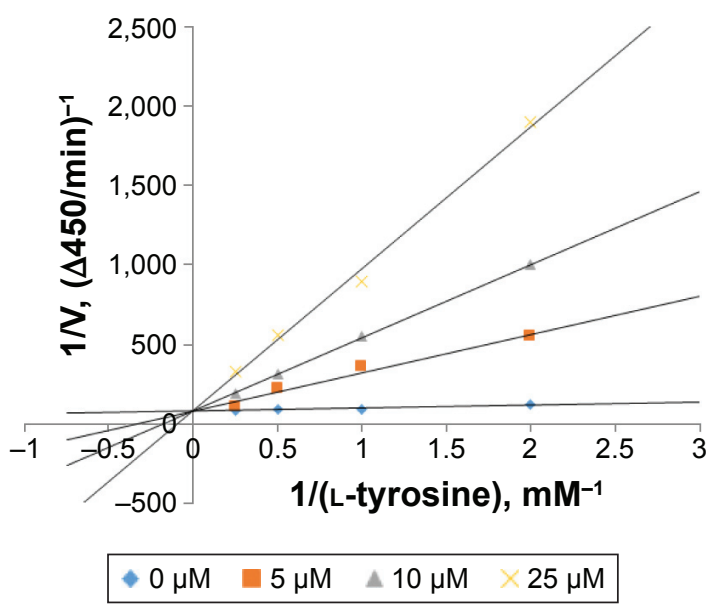

Figure 2 Mode of mushroom tyrosinase inhibition by PDTM3.

Notes: Lineweaver-Burk plots were used to determine the nature of tyrosinase inhibition by PDTM3. The results shown are mean I/V values, ie, the inverse of the increase in absorbance per minute at $0.5, \mathrm{I}, 2$, and $4 \mathrm{mM}$ of L-tyrosine. The modified Michaelis-Menten equation was used: $I / \mathrm{V}_{\max }=1 / \mathrm{K}_{\mathrm{m}}\left(\mathrm{I}+[\mathrm{S}] / \mathrm{K}_{\mathrm{i}}\right)$, where $\mathrm{V}$ is velocity of the reaction, $\mathrm{S}$ is concentration of the L-tyrosine, $\mathrm{K}_{\mathrm{m}}$ is Michaelis constant, and $\mathrm{K}$ is inhibition constant.

Abbreviation: PDTM, (2-substituted phenyl-I,3-dithiolan-4-yl)methanol.

velocity $\left(\mathrm{V}_{\max }\right)$ was not affected by PDTM3 concentration. These findings demonstrate PDTM3 dose dependently and competitively inhibited tyrosinase.

\section{In silico docking simulations of association of tyrosinase with PDTM3, PDTM7-PDTM9, PDTMI3, and kojic acid}

AutoDock Vina was utilized to determine whether the synthesized PDTM analogues directly inhibited tyrosinase through binding to its active site. Kojic acid and five PDTM analogues (PDTM3, PDTM7-PDTM9, and PDTM13), which were found to have potent mushroom tyrosinaseinhibitory activity, were used as ligands for the docking simulation. Each of these PDTM analogues could have four stereoisomers, and binding energies of the stereoisomers are indicated in Figure 3A. All five PDTM analogues were found to have similar or higher affinity for the active site

Table 2 Kinetic parameters of mushroom tyrosinase in the presence of PDTM3

\begin{tabular}{llll}
\hline Concentration $(\mu \mathbf{M})$ & $\mathbf{V}_{\max }\left(\mathbf{m} \mathbf{M} \cdot \mathbf{m i n}^{-1}\right)$ & $\mathbf{K}_{\mathrm{m}}(\mathbf{m M})$ & $\mathbf{K}_{\mathrm{i}}(\mathbf{M})$ \\
\hline 0 & 0.0123 & 0.229 & \\
5 & 0.0123 & 2.973 & $4.17 \times 10^{-7}$ \\
10 & 0.0123 & 5.676 & $4.20 \times 10^{-7}$ \\
25 & 0.0123 & 11.005 & $5.31 \times 10^{-7}$ \\
\hline
\end{tabular}

Notes: Data are representative of three independent experiments using different concentrations of L-tyrosine as a substrate. $\mathrm{V}_{\max }$ was obtained by measuring the increase in the optical density at $475 \mathrm{~nm}$ per minute.

Abbreviations: $V_{\max }$, maximum velocity; $\mathrm{K}_{\mathrm{m}}$, Michaelis constant; $\mathrm{K}_{i}$, inhibition constant. of tyrosinase compared to kojic acid $(-5.4 \mathrm{kcal} / \mathrm{mol})$, and PDTM3 demonstrated greatest affinity. This result indicated that the strong inhibitory effects of these five PDTM derivatives were attributable to their binding affinity with tyrosinase, and showed a close relationship between binding affinity, as determined by docking simulation, and tyrosinase inhibition.

LigandScout 3.1.2 was used to identify tyrosinase amino acid residues that interact with PDTM analogues. As shown in Figure 3B and C, the 4-hydroxyl group on the phenyl ring of PDTM3 interacted with His 85 of tyrosinase through hydrogen bonding and the phenyl ring interacted with Val283 and Ala286 through hydrophobic interactions and with His 263 through $\pi-\pi$ stacking interaction. Hydrogen bonding between the alcoholic hydroxyl group and amino acid residues of tyrosinase was detected only for PDTM7 and PDTM8. However, the alcoholic hydroxyl group of both PDTM analogues interacted with different amino acid residues, eg, PDTM7 interacted with His244 and Asn260, whereas PDTM8 interacted with Gly281. Furthermore, Val283 of tyrosinase was involved in hydrophobic interactions with all five analogues.

\section{Cell-viability assays}

The possible cytotoxicity of PDTM3, the most potent tyrosinase inhibitor, was examined by determining B16F10 cell (a melanoma cell line) viability using MTT assays. After 24 hours of treatment with 5, 10, or $25 \mu \mathrm{M}$ of PDTM3, cell viability was $99.9 \%, 98.4 \%$, and $97.4 \%$ versus untreated controls (Figure 4). This result indicates that PDTM3 at a concentration of $\leq 25 \mu \mathrm{M}$ is not cytotoxic.

\section{Melanin-content assays}

B16F10 cells were used to evaluate the depigmenting activities of the PDTM analogues. PDTM3 was chosen for the cell-based experiments, due to its potent mushroom tyrosinase-inhibitory effect and its lack of toxicity to B16F10 cells. PDTM3 was evaluated for its inhibitory effect against $\alpha$-MSH-stimulated melanogenesis in B16F10 cells by determining melanin levels in the cells. Melanin levels were significantly reduced after cells were cotreated with PDTM3 and $\alpha$-MSH compared with cells treated with $\alpha-\mathrm{MSH}$ alone. Over the concentration range $0-25 \mu \mathrm{M}$, PDTM3 exhibited a significant and dose-dependent antimelanogenic effect. Furthermore, at a concentration of only $10 \mu \mathrm{M}$, PDTM3 showed higher inhibitory potency than kojic acid at $25 \mu \mathrm{M}$, as depicted in Figure 5. These results indicated the antimelanogenic effect of PDTM3 in B16F10 cells was not related to cytotoxicity. 
A

\begin{tabular}{lll}
\hline Compound & \multicolumn{2}{l}{ Tyrosinase docking score } \\
\cline { 2 - 3 } & $\mathbf{( 2 R , 4 S ) / ( 2 S , 4 R )}$ & $\mathbf{( 2 R , 4 R ) / ( 2 S , 4 S )}$ \\
\hline PDTM3 & $-6.0 /-5.8 \mathrm{kcal} / \mathrm{mol}$ & $-5.8 /-6.4 \mathrm{kcal} / \mathrm{mol}$ \\
PDTM7 & $-5.3 /-5.8 \mathrm{kcal} / \mathrm{mol}$ & $-5.2 /-5.5 \mathrm{kcal} / \mathrm{mol}$ \\
PDTM8 & $-5.6 /-5.5 \mathrm{kcal} / \mathrm{mol}$ & $-5.2 /-5.4 \mathrm{kcal} / \mathrm{mol}$ \\
PDTM9 & $-5.3 /-5.5 \mathrm{kcal} / \mathrm{mol}$ & $-5.2 /-5.4 \mathrm{kcal} / \mathrm{mol}$ \\
PDTM13 & $-5.9 /-5.5 \mathrm{kcal} / \mathrm{mol}$ & $-6.0 /-6.1 \mathrm{kcal} / \mathrm{mol}$ \\
Kojic acid & $-5.4 \mathrm{kcal} / \mathrm{mol}$ & \\
\hline
\end{tabular}

B

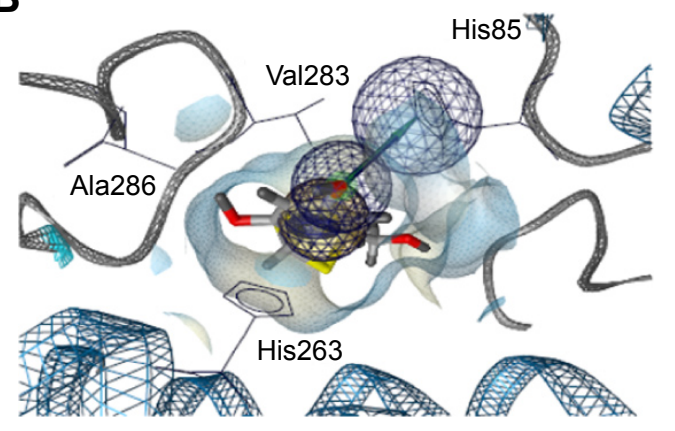

C

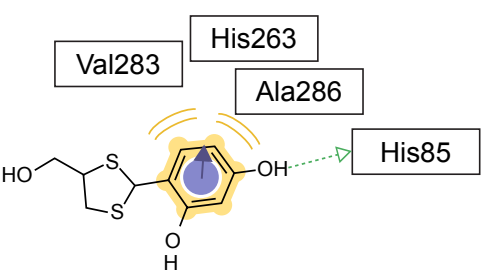

(2S,4S)-PDTM3

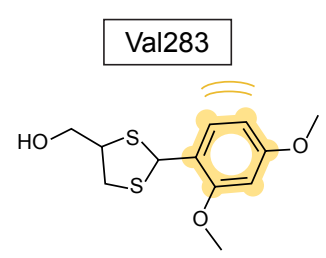

(2S,4R)-PDTM9

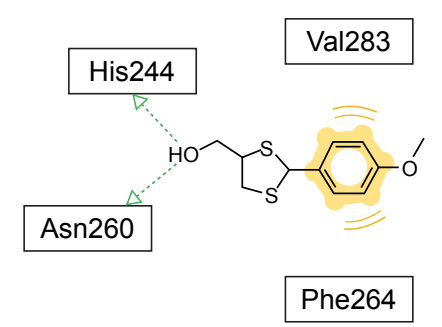

(2S,4R)-PDTM7

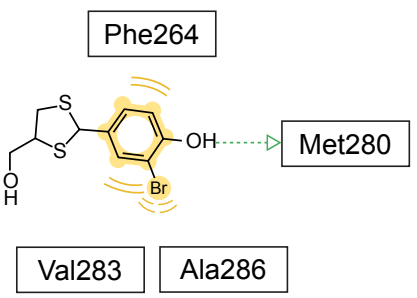

(2S,4S)-PDTM13

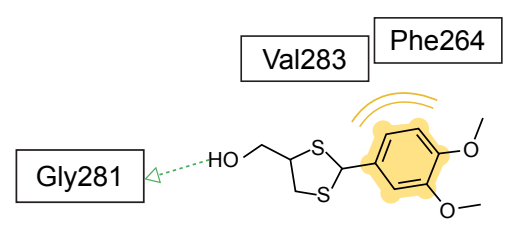

$(2 R, 4 S)-P D T M 8$

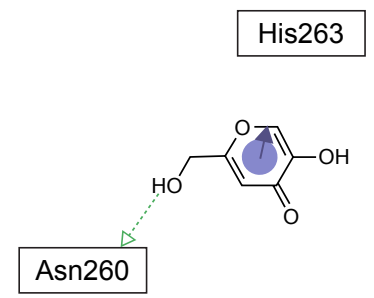

Kojic acid

Figure 3 Docking simulation of PDTM derivatives and kojic acid with tyrosinase.

Notes: (A) Tyrosinase docking scores of the five PDTM analogues and kojic acid. (B) Docking result between (2S,4S)-PDTM3 and mushroom tyrosinase. (C) The pharmacophore model obtained by the LigandScout 3.1.2 program indicated possible hydrophobic (yellow), hydrogen-bonding (green arrow), and $\pi-\pi$ stacking (violet arrow) interactions between the amino acid residues of tyrosinase and the ligands tested.

Abbreviation: PDTM, (2-substituted phenyl-I,3-dithiolan-4-yl)methanol.

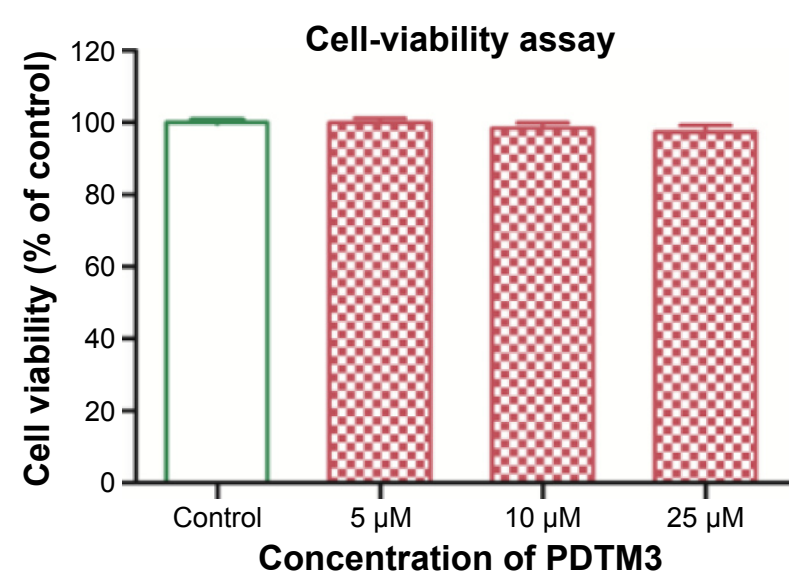

Figure 4 Effect of PDTM3 on BI6FIO cell viability.

Notes: Cell viability after treatment with PDTM3 at different concentrations for 24 hours presented as mean percentage viability against untreated controls. All experiments were independently conducted in triplicate. Bars represent standard error of the mean.

Abbreviation: PDTM, (2-substituted phenyl-I,3-dithiolan-4-yl)methanol.

\section{Tyrosinase-activity assay in BI6FIO cells}

The inhibitory effect of PDTM3 on cellular tyrosinase activity was examined in $\mathrm{B} 16 \mathrm{~F} 10$ cells prestimulated with $\alpha$-MSH. PDTM3 dose dependently inhibited tyrosinase activity over the concentration range $0-25 \mu \mathrm{M}$ (Figure 6). Furthermore, these results matched melanincontent results well, which suggested that the antimelanogenic effect of PDTM3 was attributable to the inhibition of tyrosinase.

\section{Effect on DPPH radical scavenging activity} The effect of PDTM derivatives on DPPH radical scavenging activity was investigated. PDTM4 exhibited similar DPPH radical scavenging activity to L-ascorbic acid and PDTM6, PDTM16, and PDTM17 also showed significantly potent activity, as shown in Figure 7. However, PDTM3, showing 


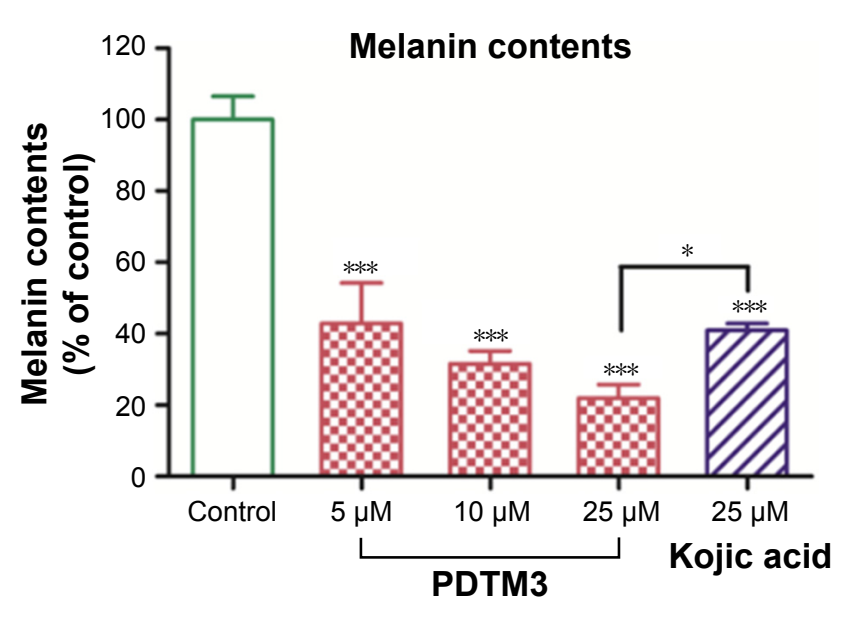

Figure 5 Antimelanogenic effect of PDTM3 in $\alpha-M S H$-stimulated BI6FIO cells. Notes: BI6FIO cells were treated with I $\mu \mathrm{M} \alpha-\mathrm{MSH}$ and then exposed to kojic acid $(25 \mu \mathrm{M})$ or PDTM3 $(0,5,10$, or $25 \mu \mathrm{M})$ for 24 hours. Inhibitions of melanin production are indicated as mean percentage inhibitions to that of the $\alpha-M S H$ only-treated control cells. Results expressed as mean \pm standard error of three independent experiments. One-way analysis of variance followed by Dunnett's test was used to determine whether group means differed significantly from those of controls. Unpaired Welch's $t$-test was used to determine whether the effects of PDTM3 and kojic acid were significantly different. $* P<0.05 ; * * * P<0.001$.

Abbreviations: PDTM, (2-substituted phenyl-1,3-dithiolan-4-yl)methanol; MSH, melanocyte-stimulating hormone.

the greatest tyrosinase-inhibitory activity, exerted only moderate DPPH radical scavenging potency.

We showed through this study that the 1,3-dithiolane ring is a promising chemical scaffold that can inhibit the activity of tyrosinase and that PDTM3 bearing the scaffold not only inhibits the tyrosinase enzyme itself but also has antimelanogenic effects in a cell-based system. The

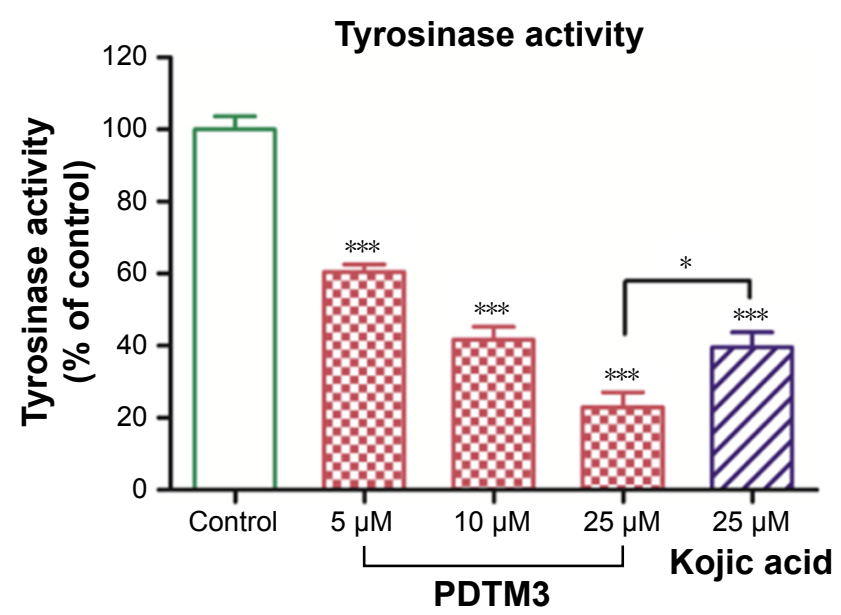

Figure 6 Effect of PDTM3 on tyrosinase activity in BI6FI0 cells.

Notes: BI6FIO cells were prestimulated with I $\mu \mathrm{M} \alpha-\mathrm{MSH}$ and then treated with PDTM3 $(0,5,10$, or $25 \mu \mathrm{M})$ or kojic acid $(25 \mu \mathrm{M})$ for 24 hours. Tyrosinaseactivity inhibition is indicated as mean percentages compared to that of the $\alpha-M S H$ only-treated control cells. Results expressed as mean \pm standard error of three independent experiments. One-way analysis of variance followed by Dunnett's test was used to determine whether group means differed significantly from those of controls. Unpaired Welch's $t$-test was used to determine whether the effects of PDTM3 and kojic acid were significantly different. $* P<0.05$; $* * * P<0.001$.

Abbreviations: PDTM, (2-substituted phenyl-1,3-dithiolan-4-yl)methanol; MSH, melanocyte-stimulating hormone.

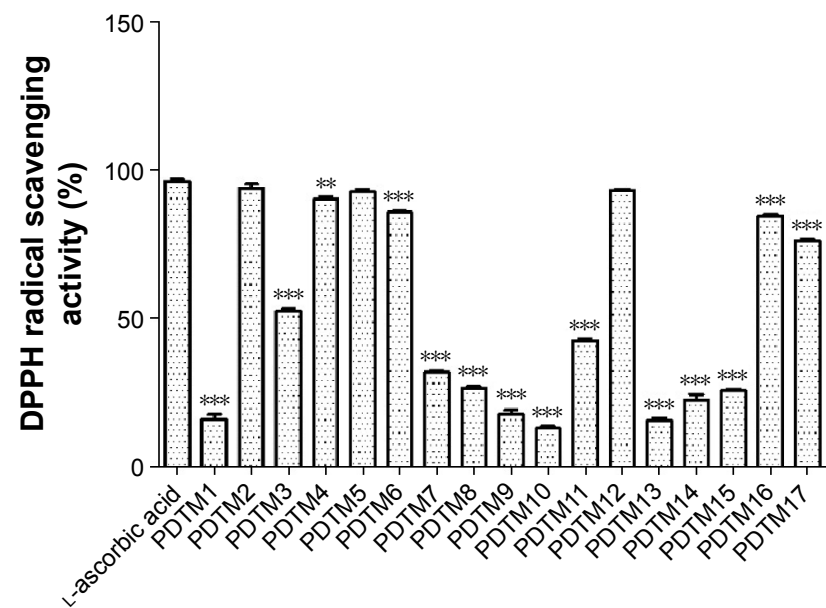

Figure 7 The effect of PDTM derivatives on DPPH radical scavenging activity. Notes: After 30 minutes in the dark, the radical scavenging activity of each compound was assayed at a concentration of I mM. Asterisks indicate a significant difference between PDTMs and L-ascorbic acid. Results expressed as mean \pm standard error of three independent experiments. One-way analysis of variance followed by Dunnett's test was used to determine whether group means differed significantly from those of controls. $* * p<0.01$; $* * * p<0.001$.

Abbreviations: PDTM, (2-substituted phenyl-I,3-dithiolan-4-yl)methanol; DPPH, 2,2-diphenyl-I-picrylhydrazyl.

limitation of this study - the activity test of PDTMs without separation of the racemates - will be overcome after finding methods of separating them in the future.

\section{Conclusion}

In this work, a variety of PDTM analogues were synthesized and evaluated for their effects on melanogenesis and tyrosinase activity in B16F10 cells. Eight analogues exhibited as much or more potent inhibition against mushroom tyrosinase than kojic acid, and PDTM3 had the greatest inhibitory activity. In B16F10 cells, PDTM3 significantly inhibited melanin biosynthesis in a dose-dependent manner and tyrosinase activity over the concentration range $0-25 \mu \mathrm{M}$ with no cytotoxic effect. At a concentration of $10 \mu \mathrm{M}$, PDTM3 reduced melanin biosynthesis and tyrosinase activity significantly more than kojic acid at $25 \mu \mathrm{M}$. In view of our observation that many PDTM analogues showed potent tyrosinase-inhibitory activities, we suggest that 1,3-dithiolane be considered an appropriate scaffold for tyrosinase-inhibitory activity. Now, we are looking for separation conditions of each PDTM mixture of two racemates, and the separation conditions and antimelanogenic effect of each single racemate will be reported in due course.

\section{Acknowledgment}

This work was supported by a National Research Foundation of Korea (NRF) grant funded by the Korean government (MSIP; grant number 2009-0083538). 


\section{Disclosure}

The authors report no conflicts of interest in this work.

\section{References}

1. Raper HS. The aerobic oxidases. Physiol Rev. 1928;8:245-282.

2. Mason HS. The chemistry of melanin: mechanism of the oxidation of dihydroxyphenylalanine by tyrosinase. J Biol Chem. 1948;172: $83-99$.

3. Cooksey CJ, Garratt PJ, Land EJ, et al. Evidence of the indirect formation of the catecholic intermediate substrate responsible for the autoactivation kinetics of tyrosinase. J Biol Chem. 1997;272: 26226-26235.

4. Schallreuter KU, Kothari S, Chavan B, Spencer JD. Regulation of melanogenesis: controversies and new concepts. Exp Dermatol. 2008;17: 395-404.

5. Halaban R, Patton RS, Cheng E, et al. Abnormal acidification of melanoma cells induces tyrosinase retention in the early secretory pathway. J Biol Chem. 2002;277:14821-14828.

6. Artés F, Castaner M, Gil MI. Enzymatic browning in minimally processed fruit and vegetables. Food Sci Technol Int. 1998;4:377-389.

7. Rescigno A, Sollai F, Pisu B, Rinaldi A, Sanjust E. Tyrosinase inhibition: general and applied aspects. J Enzyme Inhib Med Chem. 2002;17: 207-218.

8. Kim YJ, Uyama H. Tyrosinase inhibitors from natural and synthetic sources: structure, inhibition mechanism and perspective for the future. Cell Mol Life Sci. 2005;62:1707-1723.

9. Parvez S, Kang M, Chung HS, Bae H. Naturally occurring tyrosinase inhibitors: mechanism and applications in skin health, cosmetics and agriculture industries. Phytother Res. 2007;21:805-816.

10. Han YK, Park YJ, Ha YM, et al. Characterization of a novel tyrosinase inhibitor, (2RS,4R)-2-(2,4-dihydroxyphenyl)thiazolidine-4-carboxylic acid (MHY384). Biochim Biophys Acta. 2012;1820:542-549.

11. Chung KW, Jeong HO, Jang EJ, et al. Characterization of a small molecule inhibitor of melanogenesis that inhibits tyrosinase activity and scavenges nitric oxide (NO). Biochim Biophys Acta. 2013;1830: 4752-4761.

12. Napolitano A, Micillo R, Monfrecola G. Melanin pigmentation control by 1,3-thiazolidines: does NO scavenging play a critical role? Exp Dermatol. 2016;25:596-597.

13. Moon KM, Jeong JW, Lee B, et al. Antimelanogenic activity of MHY384 via inhibition of NO-induced cGMP signalling. Exp Dermatol. 2016;25:652-654.

14. Ohkuma T, Imai M, Nakamura M, Otsuji A, inventors; Mitsui Chemicals, assignee. Acrylic ester compound and usage thereof. European patent EP1193264 A1. 2002 Apr 3.

15. Hyun SK, Lee WH, Jeong DM, Kim Y, Choi JS. Inhibitory effects of kurarinol, kuraridinol, and trifolirhizin from Sophora flavescens on tyrosinase and melanin synthesis. Biol Pharm Bull. 2008;31: $154-158$.

16. Moustakas DT, Lang PT, Pegg S, et al. Development and validation of a modular, extensible docking program: DOCK 5. J Comput Aided Mol Des. 2006;20:601-619.
17. Morris GM, Goodsell DS, Halliday RS, et al. Automated docking using a Lamarckian genetic algorithm and an empirical binding free energy function. J Comput Chem. 1998;19:1639-1662.

18. Shin DH, Kim OH, Jun HS, Kang MK. Inhibitory effect of capsaicin on B16-F10 melanoma cell migration via the phosphatidylinositol 3-kinase/Akt/Rac1 signal pathway. Exp Mol Med. 2008;40:486-494.

19. Chen LG, Chang WL, Lee CJ, Lee LT, Shih CM, Wang CC. Melanogenesis inhibition by gallotannins from Chinese galls in B16 mouse melanoma cells. Biol Pharm Bull. 2009;32:1447-1452.

20. Bae SJ, Ha YM, Kim JA, et al. A novel synthesized tyrosinase inhibitor: (E)-2-((2,4-dihydroxyphenyl)diazenyl)phenyl 4-methylbenzenesulfonate as an azo-resveratrol analog. Biosci Biotechnol Biochem. 2013;77:65-72.

21. Matos MJ, Varela C, Vilar S, et al. Design and discovery of tyrosinase inhibitors based on a coumarin scaffold. RSC Adv. 2015;5: 94227-94235.

22. Cabanes J, Chazarra S, Garcia-Carmona F. Kojic acid, a cosmetic skin whitening agent, is a slow-binding inhibitor of catecholase activity of tyrosinase. J Pharm Pharmacol. 1994;46:982-985.

23. Maeda K, Fukuda M. Arbutin: mechanism of its depigmenting action in human melanocyte culture. J Pharmacol Exp Ther. 1996;276: 765-769.

24. Ha YM, Park JY, Park YJ, et al. Synthesis and biological activity of hydroxy substituted phenyl-benzo[d] thiazole analogues for antityrosinase activity in B16 cells. Bioorg Med Chem Lett. 2011;21:2445-2449.

25. Chung KW, Park YJ, Choi YJ, et al. Evaluation of in vitro and in vivo anti-melanogenic activity of a newly synthesized strong tyrosinase inhibitor (E)-3-(2,4 dihydroxybenzylidene)pyrrolidine-2,5-dione (3-DBP). Biochim Biophys Acta. 2012;1820:962-969.

26. Bae SJ, Ha YM, Park YJ, et al. Design, synthesis, and evaluation of (E)-N-substituted benzylidene-aniline derivatives as tyrosinase inhibitors. Eur J Med Chem. 2012;57:383-390.

27. Kim SH, Ha YM, Moon KM, et al. Anti-melanogenic effect of (Z)-5(2,4-dihydroxybenzylidene) thiazolidine-2,4-dione, a novel tyrosinase inhibitor. Arch Pharm Res. 2013;36:1189-1197.

28. Park JW, Ha YM, Moon KM, et al. De novo tyrosinase inhibitor:4-(6,7dihydro-5H-indeno[5,6-d]thiazol-2-yl)benzene-1,3-diol (MHY1556). Bioorg Med Chem Lett. 2013;23:4172-4176.

29. Kim SH, Choi YJ, Moon KM, et al. The inhibitory effect of a synthetic compound, (Z)-5-(2,4-dihydroxybenzylidene) thiazolidine-2,4-dione (MHY498), on nitric oxide-induced melanogenesis. Bioorg Med Chem Lett. 2013;23:4332-4335.

30. Kim HR, Lee HJ, Choi YJ, et al. Benzylidene-linked thiohydantoin derivatives as inhibitors of tyrosinase and melanogenesis: importance of the $\beta$-phenyl- $\alpha, \beta$-unsaturated carbonyl functionality. Med Chem Commun. 2014;5:1410-1417.

31. Kang KH, Lee B, Son S, et al. (Z)-2-(benzo[d]thiazol-2-ylamino)5-(substituted benzylidene)thiazol-4(5H)-one derivatives as novel tyrosinase inhibitors. Biol Pharm Bull. 2015;38:1227-1233.

32. Lee B, Moon KM, Kim SJ, et al. (Z)-5-(2,4-dihydroxybenzylidene) thiazolidine-2,4-dione prevents UVB-induced melanogenesis and wrinkle formation through suppressing oxidative stress in HRM-2 hairless mice. Oxid Med Cell Longev. 2016;2016:2761463.
Drug Design, Development and Therapy

\section{Publish your work in this journal}

Drug Design, Development and Therapy is an international, peerreviewed open-access journal that spans the spectrum of drug design and development through to clinical applications. Clinical outcomes, patient safety, and programs for the development and effective, safe, and sustained use of medicines are the features of the journal, which

\section{Dovepress}

has also been accepted for indexing on PubMed Central. The manuscript management system is completely online and includes a very quick and fair peer-review system, which is all easy to use. Visit http://www.dovepress.com/testimonials.php to read real quotes from published authors. 